\title{
Durabilidad del hormigón: Influencia de la adición de escoria a un cemento portland resistente a los sulfatos. Acción del agua de mar y de una disolución saturada de yeso
}

\author{
DEMETRIO GASPAR-TEBAR y JOSE LUIS SAGRERA-MORENO, ICCET/CSIC. MADRID \\ MANUEL AGUANELL GARCÍA, Cementos Valderrivas, S.A. MADRID \\ VICTORIANO GONZALEZ VILA, Cementos del Atlántico, S.A. SEVILLA.
}

\begin{abstract}
RESUMEN
En este artículo se estudia la influencia de la adición de distintas cantidades de escoria, comparándola con la adición de arena silícea, finamente molida, cuando las probetas de mortero $(1: 3)$ de $1 \times 1 \times 6 \mathrm{~cm}$-preparadas con un cemento portland resistente a los sulfatos, con sus mezclas con una escoria seleccionada y con la arena silicea- se someten a la acción del agua de mar artificial ASTM y de una disolución saturada de yeso durante diversos periodos de tiempo (hasta 3 años las primeras y 1 año las segundas), determinando la evolución de las resistencias mecánicas (a flexotracción), de los coeficientes de corrosión Koch-Steinegger, de la composición estructural de las nuevas fases sólidas formadas en los medios de curado y de conservación-ataque, así como de la pasta hidratada-atacada del cemento y de sus mezclas con la escoria y con la arena silícea extraida de la probeta de mortero, y la variación de la concentración de los iones $\mathrm{Ca}$ (II) y $\mathrm{Mg}$ (II).
\end{abstract}

Asimismo, se estudia la evolución de las resistencias mecánicas de las probetas de mortero de $4 \times 4 \times 16 \mathrm{~cm} \mathrm{y}$ de hormigón de $10 \times 10 \times 40 \mathrm{~cm}$, fabricadas con dicho cemento y sometidas a la acción de las disoluciones mencionadas durante diversos periodos de tiempo (hasta 5 años). Por último, se da cuenta de los trabajos iniciados, desde este punto de vista, en un lugar seleccionado del Puerto Autónomo de Huelva.

\section{SUMMARY}

This article studies the influence of addition of different quantities of slag and compares this with the addition of fine particled silica sand. The mortar samples (1:3) of 1 $\times 1 \times 6 \mathrm{~cm}$-prepared with a sulphate-resistent portland cement, mixed with a selected slag and with silica sandwere subjected to the action of artificial sea water ASTM and to a saturated plaster disolution for different periods of time (3 years for the first and 1 year for second ones). The performance of the following factors was determined: the mechanical resistence (to flexotraction), the KochSteinegger corrosion coefficients, the structural composition of the new solid phases formed in the cured medium and the preservation-attack. The following were also examined: the hidrated-attacked cement paste and its mixes with the slag and the silica sand taken from the mortar sample, and the variation in concentration of $\mathrm{Ca}$ (II) and $\mathrm{Mg}$ (II) ions.

The performance in mechanical resistence of samples of mortar measuring $4 \times 4 \times 16 \mathrm{~cm}$ and of concrete measuring $10 \times 10 \times 40 \mathrm{~cm}$ were also studied in this way. These samples were made with the aforementioned cement and subjected to the action of the said disolutions for different periods of time (up till 5 years). Finally, an account is given of work which has been started on this subject at a selected area at the Autonomous Port of Huelva.

\section{PALABRAS CLAVE:}

DURABILIDAD HORMIGÓN-ACCIÓN AGUA MAR Y DISOLUCIONES YESO-CEMENTOS-ESCORIAS.

\section{INTRODUCCIÓN}

Con objeto de ampliar el conocimiento sobre el comportamiento mecánico-resistente de los cementos portland hidratados y sobre todo de sus mezclas con adiciones naturales y artificiales, sometidos a la acción del agua de mar y de disoluciones agresivas, asi como sobre el mecanismo de las reacciones que tienen lugar, se ha realizado este trabajo que forma parte de un Programa de Investigación del
ICCET a desarrollar a largo plazo, tanto a escala de laboratorio como a escala real (1).

\section{PARTE EXPERIMENTAL}

En este trabajo se da cuenta de los resultados obtenidos cuando las probetas de mortero (1:3) de $1 \times 1 \times 6 \mathrm{~cm}$, de $4 \times 4 \times 16 \mathrm{~cm}$ y de hormigón de $10 \times 10 \times 40 \mathrm{~cm}$ hechas con un cemento portland resistente a los sulfatos (cemento 2) -así como las probetas de mortero (1:3) de $1 \times 1 \times 6 \mathrm{~cm}$ elaboradas con las mezclas de dicho cemento con una escoria granulada de horno alto y con arena silícea molida - se someten a la acción del agua de mar artificial ASTM D 1141-76, de una disolu- 
ción saturada de sulfato de calcio hidratado (yeso) y de agua potable filtrada (probetas de $1 \times 1 \times 6 \mathrm{~cm}$ ) o de agua potable (resto de las probetas) durante distintos períodos de tiempo, determinando la evolución:

a) De las resistencias mecánicas, a flexotracción, de las probetas de mortero (1:3) de $1 \times 1 \times 6 \mathrm{~cm}$ hechas con el cemento 2 , sumergidas en las disoluciones agresivas $y$ en el agua potable filtrada durante 56 días y $3,6,9,12,18,24,30$ y 36 meses, después del período de curado $(1+21$ días).

b) De las resistencias mecánicas, a flexotracción y compresión de las probetas de mortero $(1: 3)$ de $4 \times 4 \times 16 \mathrm{~cm}$ y de hormigón de $10 \times 10 \times 40 \mathrm{~cm}$ elaboradas con el cemento 2, sumergidas en las disoluciones agresivas mencionadas y en agua potable, después del período de curado $(1+30$ días), durante $3,6,9,12,18,24,30,36,42$, 48,54 y 60 meses.

c) De las resistencias mecánicas, a flexotracción, de las probetas de mortero (1:3) de $1 \times 1 \times 6 \mathrm{~cm}$ fabricadas con las mezclas cemento $2 /$ escoria $=85 / 15-65 / 35-40 / 60$ y $30 / 70$ (en peso), sumergidas en las dos disoluciones agresivas reseñadas y en agua potable filtrada, después del período de curado ( $1+21$ días), durante 56 días 3 , $6,9,12,18,24,30$ y 36 meses y con mezclas análogas de cemento 2/arena molida, sumergidas en dichas disoluciones y en agua potable filtrada durante 56 días y $3,6,9$ y 12 meses.

Asimismo, en este trabajo se da cuenta de la composición estructural de la nueva fase sólida formada en los medios de curado (agua potable filtrada) y de conservación-ataque (agua potable filtrada, agua de mar artificial y disoluciones saturadas de yeso) en donde han estado sumergidas las probetas de mortero $(1: 3)$ de $1 \times 1 \times 6 \mathrm{~cm}$ durante los primeros periodos de tiempo (56 - 90 - 180 y 360 días), así como de la pasta hidratada atacada de dichas probetas y de la evolución de los contenidos de los iones $\mathrm{Ca}$ (II), $\mathrm{SO}_{4}$ (II) y, además, $\mathrm{Mg}$ (II), según los medios de conservación-ataque.

\subsection{Materiales utilizados}

\subsubsection{Cemento}

Se ha utilizado un cemento portland industrial resistente a los sulfatos, el cual se ha designado cemento 2, cuya composición química y potencial calculada (Bogue), así como la superficie específica, se encuentra en la tabla 1.
TABLA I

\begin{tabular}{|c|c|c|}
\hline $\begin{array}{l}\text { 1. Análisis químico } \\
(\% \text {, en masa })\end{array}$ & $\begin{array}{l}\text { Cemen- } \\
\text { to } 2\end{array}$ & $\begin{array}{c}\text { Esco- } \\
\text { ria }\end{array}$ \\
\hline Pérdida por calcinación & 1,1 & 0,4 \\
\hline Residuo insoluble, R.I. & 0,2 & 0,0 \\
\hline Dióxido de silicio, $\mathrm{SiO}_{2}$ & 22,0 & 35,2 \\
\hline Oxido de hierro (III), $\mathrm{Fe}_{2} \mathrm{O}_{3}$ & 4,1 & 0,7 \\
\hline Oxido de aluminio, $\mathrm{Al}_{2} \mathrm{O}_{3}$ & 1,8 & 17,0 \\
\hline Oxido de calcio, $\mathrm{CaO}$ & 67,9 & 37,3 \\
\hline Oxido de magnesio, $\mathrm{MgO}$ & 0,5 & 6,3 \\
\hline Trióxido de azufre, $\mathrm{SO}_{3}$ & 2,3 & 0,0 \\
\hline Manganeso (II) & n.d. & 0,8 \\
\hline Suma & 99,9 & 97,7 \\
\hline $\begin{array}{l}\text { CaO libre } \\
\text { n.d. = no determinado }\end{array}$ & 1,8 & \\
\hline \multicolumn{3}{|l|}{$\begin{array}{l}\text { 2. Composición potencial } \\
\text { (Bogue) }\end{array}$} \\
\hline $\mathrm{C}_{3} \mathrm{~S}$ & 75,6 & \\
\hline $\mathrm{C}_{2} \mathrm{~S}$ & 6,1 & \\
\hline $\mathrm{C}_{3} \mathrm{~A}$ & 0,0 & \\
\hline $\mathrm{C}_{4} \mathrm{AF}$ & 10,8 & \\
\hline \multicolumn{3}{|l|}{$\begin{array}{l}\text { 3. Superficie especifica } \\
\text { (Blaine) }\end{array}$} \\
\hline $\mathrm{cm}^{2} / \mathrm{g}$ & 3.553 & \\
\hline
\end{tabular}

En la figura 1 se incluyen los DRX del cemento y del residuo insoluble en ácido salicílicometanol (zonas de las fases cristalinas correspondientes a los aluminatos) de dicho cemento.

\subsubsection{Adiciones}

De entre las adiciones estudiadas en una primera etapa se han seleccionado, para realizar este trabajo, una escoria granulada de horno alto $y$, además, arena silícea molida para utilizarla como control.

\section{a) Escoria}

Se ha empleado la escoria granulada de horno alto, cuyo análisis químico y difractograma de rayos $X$ se representan en la tabla 1 y en la figura 2. 


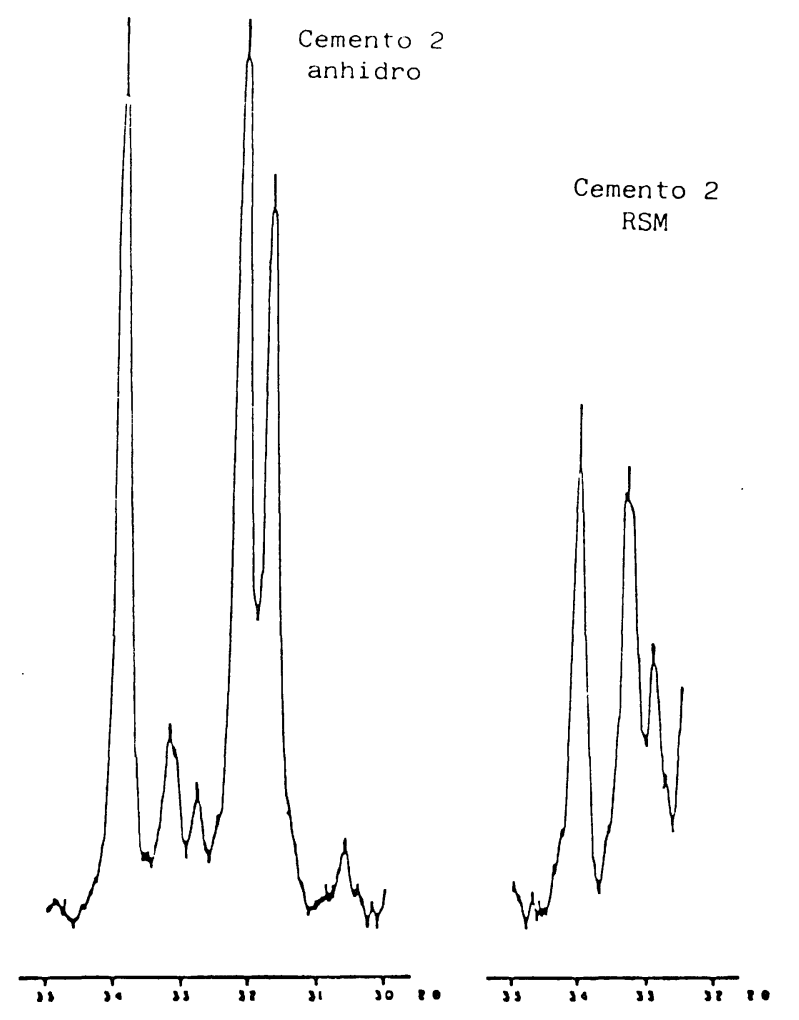

Fig. 1.-DRX del cemento 2 anhidro y del RSM.

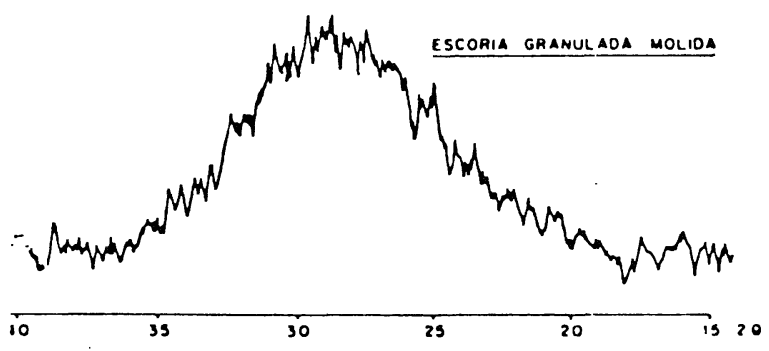

Fig. 2.-DRX de la escoria granulada.

\section{b) Arena}

Se ha utilizado, como adición al cemento, una arena silícea molida hasta que ha pasado -toda ella- por un tamiz de $88 \mu \mathrm{m}$. Esta arena tiene una riqueza en $\mathrm{SiO}_{2}$ superior al $99 \%$.

\subsubsection{Disoluciones agresivas}

Como disoluciones agresivas se han utilizado agua de mar artificial ASTM y una disolución saturada de sulfato de calcio dihidratado, que se han preparado del siguiente modo:

\section{a) Agua de mar artificial ASTM}

El agua de mar artificial se ha preparado según el punto 6 de la norma ASTM D 1141-75. El contenido de los iones, que se citan a continuación, y el valor del $\mathrm{pH}$-determinados experimentalmente- es el siguiente: $\mathrm{Ca}$ (II) $=$ $=0,521 \mathrm{~g} / \mathrm{l}<>1,30 \times 10^{-2}$ moles/litro; $\mathrm{Mg}(\mathrm{II})=$ $=1,347 \mathrm{~g} / \mathrm{l}\left\langle>5,54 \times 10^{-2}\right.$ moles/litro; $\mathrm{SO}_{4}$ (II) $=2,928 \mathrm{~g} / \mathrm{l}<>3,04 \times 10^{-2}$ moles/litro; $\mathrm{Cl}$ (I) $=19,585 \mathrm{~g} / \mathrm{l}<>5,52 \times 10^{-2}$ moles/litro y $\mathrm{pH}=6,5$.

b) Disolución saturada de sulfato de calcio dihidratado

La disolución saturada de sulfato de calcio dihidratado se ha obtenido a partir de yeso natural, con una riqueza de $\mathrm{CaSO}_{4} .2 \mathrm{H}_{2} \mathrm{O}$ superior al $98 \%$, determinada por vía química y por DRX. El contenido de los iones $\mathrm{SO}_{4}$ (II) y $\mathrm{Ca}$ (II) de la disolución, determinado experimentalmente, es el siguiente: $\mathrm{SO}_{4}$ (II) $=1,099$ $\mathrm{g} / \mathrm{l}<>1,14 \times 10^{-2}$ moles/litro y $\mathrm{Ca}$ (II) $=$ $=0,459 \mathrm{~g} / \mathrm{l}<>1,14 \times 10^{-2}$ moles/litro.

\section{c) Agua potable y agua potable filtrada}

Como medio de curado y de conservación de las probetas de mortero $(1: 3)$ de $4 \times 4 \times 16$ $\mathrm{cm}$ y de hormigón $10 \times 10 \times 40 \mathrm{~cm}$ se ha utilizado agua potable (Canal Isabel II - Madrid) y de las probetas de mortero (1:3) de $1 \times 1 \times 6 \mathrm{~cm}$ agua de dicho Canal, una vez que ha pasado a través de un filtro cerámico. El contenido de los iones, que se citan a continuación, es el siguiente: $\mathrm{Ca}(\mathrm{II})=0,005 \mathrm{~g} / \mathrm{l}$; $\mathrm{Mg}(\mathrm{II})=0,0016 \mathrm{~g} / \mathrm{l} ; \mathrm{SO}_{4}$ (II) $=0,003 \mathrm{~g} / \mathrm{l} ; \mathrm{Cl}(\mathrm{I})=$ $=0,007 \mathrm{~g} / \mathrm{l}$ y $\mathrm{pH}=7,1$.

\subsection{Preparación, curado y conservación de las probetas de mortero y hormigón}

\subsubsection{Probetas de mortero de $1 \times 1 \times 6 \mathrm{~cm}$}

Con el cemento 2 , y con las mezclas cemento $2 /$ escoria o arena $=85 / 15-65 / 35-40 / 60$ y $30 / 70$ (en peso), se han preparado las distintas series de probetas de mortero $(1: 3)$ de $1 \times 1 \times$ $\times 6 \mathrm{~cm}$ (2), habiéndose utilizado la relación $a / c=0,6$. Las probetas se han curado 1 día en cámara húmeda (a $20 \pm 1^{\circ} \mathrm{C}$, con una humedad relativa superior a $90 \%$ ) y, a continuación, bajo agua potable filtrada (a $20 \pm 2^{\circ} \mathrm{C}$ ) durante 21 días; posteriormente se han sumergido 12 probetas/1 serie/cemento o mezcla/1 edad en $800 \mathrm{ml}$ de agua potable filtrada, de agua de mar artificial (ASTM) y de la disolución saturada de yeso durante 56 - 90 - 180 y 360 días (1. a etapa) y durante $18-24-30$ y 36 meses (2. ${ }^{a}$ etapa), que se corresponden con los puntos a) y b) del apartado 2.1.3. 


\subsubsection{Probetas de mortero de $4 \times 4 \times 16 \mathrm{~cm}$}

Las diversas series de probetas de mortero de $4 \times 4 \times 16 \mathrm{~cm}$ (10 probetas $/ 1$ serie/cemento/ 1 edad/disolución) se han preparado con el cemento 2, de acuerdo con el procedimiento operatorio descrito en el Pliego General de Condiciones para la Recepción de Cementos (RC-75) (3).

Las distintas series de probetas de mortero se han curado en una cámara húmeda, análoga a la anterior, durante las primeras 24 horas y, durante 30 días, bajo agua potable a $20 \pm 2^{\circ} \mathrm{C}$. A continuación se han sumergido en agua potable y en las disoluciones mencionadas que, previamente, se han puesto en unos recipientes de asbesto-cemento protegidos con un revestimiento a base de resina epoxi. Dichos recipientes se situaron en el recinto exterior del Instituto Eduardo Torroja sometidos, por consiguiente, a las condiciones climáticas ambientes.

Las probetas se han colocado en posición vertical, separadas entre sí unos $5 \mathrm{~cm}$.

Las disoluciones agresivas fueron renovadas cuando la concentración de iones-sulfato era inferior a $500 \mathrm{mg} / \mathrm{l}$.

Los períodos de tiempo de conservación-ataque han sido $6,12,18,24,30,36,42,48,54$ y 60 meses.

\subsubsection{Probetas de hormigón de $10 \times 10 \times 40 \mathrm{~cm}$}

Las series de probetas de hormigón de $10 \times$ $\times 10 \times 40 \mathrm{~cm}$ (10 probetas/1 serie/cemento/ /edad/disolución) se han preparado con el cemento 2 y con áridos rodados silíceos y lavados, respondiendo a la curva granulométrica de Bolomey. Se han empleado $400 \mathrm{~kg}$ de cemento por $\mathrm{m}^{3}$ de hormigón y una relación $a / c=0,45$. Cada 4 probetas se han vibrado, en una mesa vibratoria, a $2.800 \mathrm{rpm}$ durante 2 minutos (1 minuto por tongada/dos tongadas probeta).

Las series de probetas de hormigón se han conservado las primeras 24 horas en la atmósfera del laboratorio $y$, a continuación, bajo agua potable filtrada durante 30 días, en unas balsas situadas al aire libre en el recinto del Instituto (Fig. 3). Posteriormente se han sumergido en agua potable $y$ en las disoluciones agresivas, que se encuentran en unas balsas análogas a las anteriores. Dichas balsas están forradas con un mortero de cemento y protegidas por un revestimiento a base de una resina epoxi. Cada balsa contiene 2.000 I de

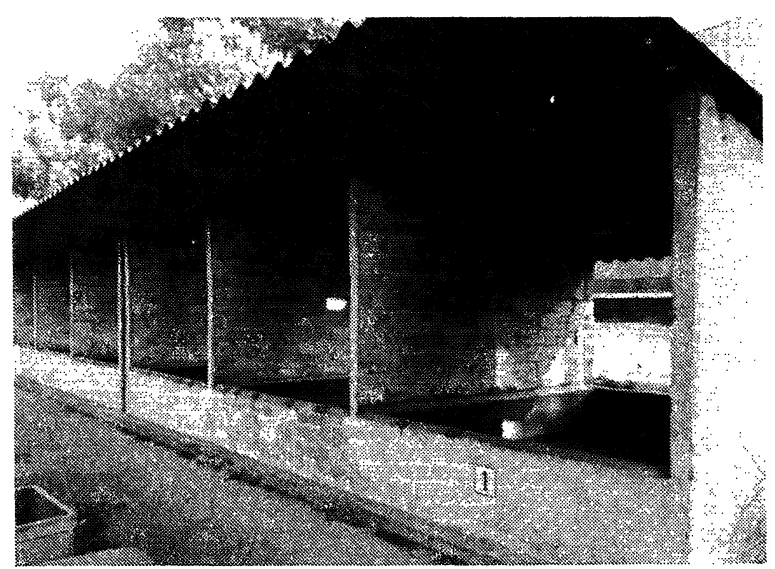

Fig. 3.-Vista depósitos probetas.

agua potable o de cada una de las disoluciones, que se han renovado cuando la concentración de iones de sulfato era inferior a 500 $\mathrm{mg} / \mathrm{l}$.

Las probetas de hormigón se han colocado en posición vertical, separadas entre sí al menos $5 \mathrm{~cm}$.

\subsection{Preparación de las fases sólidas}

La nueva fase sólida - formada en los medios en donde han estado sumergidas cada una de las series $(12$ probetas $/ 800 \mathrm{ml}$ ) de las probetas de mortero de $1 \times 1 \times 6 \mathrm{~cm}$ durante 56 , 90,180 y 360 dias (que, por el momento, se han estudiado) - se ha separado por filtración, una vez extraidas dichas probetas de mortero, y se ha secado en una corriente de nitrógeno. De estas fases sólidas se ha hecho el estudio por DRX y, posteriormente, se ha determinado su composición química.

\subsection{Preparación de la fracción enriquecida}

De uno de los prismas de cada serie de probetas de $1 \times 1 \times 6 \mathrm{~cm}$ extraidas de las disoluciones agresivas y en agua potable filtrada, donde han estado sumergidas, una vez secas en un recinto aislado de la atmósfera, se ha separado la casi totalidad de la fracción correspondiente a la arena por disgregación mecánica y, con la ayuda de un tamiz de $88 \mu \mathrm{m}$, del resto de la probeta (de la cual se ha hecho el estudio por DRX). 


\section{RESULTADOS OBTENIDOS}

\subsection{Evolución de las resistencias mecánicas}

3.1.1. Sistemas: cemento 2 - Agua potable filtrada; agua de mar artificial ASTM $y$ disolución saturada de yeso

\section{a) Probetas de mortero (1:3) de $1 \times 1 \times 6 \mathrm{~cm}$}

En la figura 4 se ha representado la evolución de las resistencias mecánicas a flexotracción, en $\mathrm{kp} / \mathrm{cm}^{2}$, de las series de probetas de mortero sumergidas en las disoluciones mencionadas, y en agua potable filtrada (valores medios de 12 probetas, por serie, por edad y por disolución agresiva), en función del tiempo de conservación (hasta 3 años). En dicha figura se observa que:

1) Las resistencias mecánicas, a flexotracción, de las probetas de mortero $(1: 3)$ de $1 \times$ $\times 1 \times 6 \mathrm{~cm}$ sumergidas en la disolución saturada de yeso, son superiores que las de las series análogas conservadas en agua potable filtrada para todas las edades, excepto para 18 y 30 meses, que son del mismo orden.

2) Las resistencias mecánicas, a flexotracción, de las probetas de mortero (1:3) de $1 \times$ $\times 1 \times 6 \mathrm{~cm}$ sumergidas en el agua de mar artificial ASTM son inferiores, con tendencia a igualarse con el tiempo de conservación, que las correspondientes a las de las series análogas conservadas en agua potable filtrada

De aquí que se establezca la siguiente escala:

Resistencias mecánicas a flexotracción de las probetas sumergidas, hasta 3 años, en disolución saturada de yeso $>$ agua potable filtrada $>$ agua de mar artificial.

Como consecuencia de estos valores, los coeficientes de corrosión Koch-Steinegger $R_{t} / R_{t}^{\prime}$, que se han representado en la figura 5 , son mayores de la unidad para las probetas conservadas en la disolución saturada de yeso y menores de la unidad, pero mayores de 0,70 para las probetas sumergidas en agua de mar artificial ASTM.

\section{b) Probetas de mortero (1:3) de $4 \times 4 \times 16 \mathrm{~cm}$}

En las figuras 6 y 7 se han representado las resistencias mecánicas de las probetas de mortero sumergidas en las disoluciones agre-

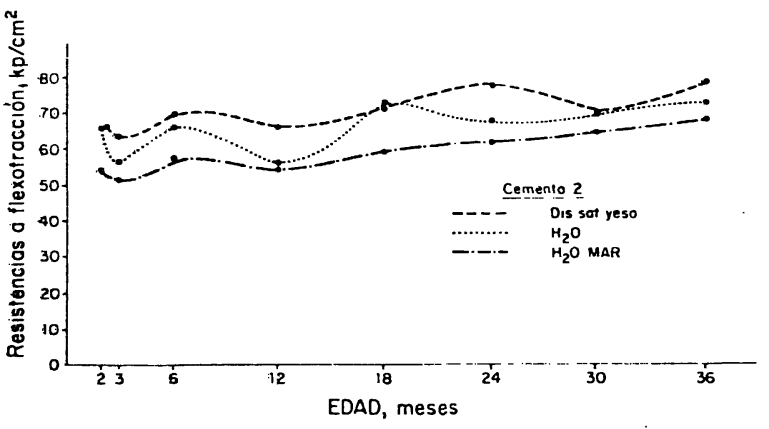

Fig. 4.-Probetas de mortero de $1 \times 1 \times 6 \mathrm{~cm}$. Evolución de las resistencias mecánicas, a flexotracción.

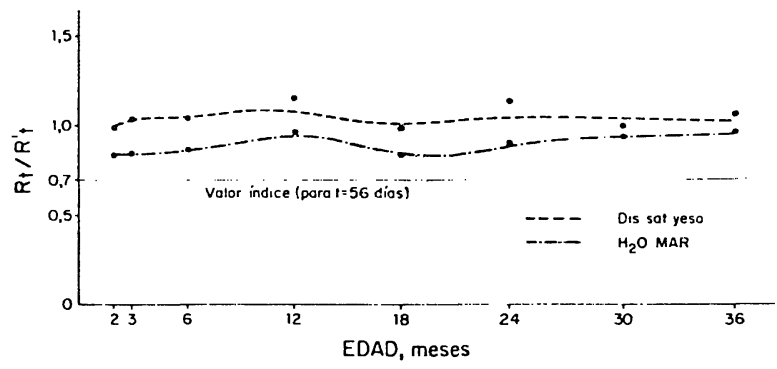

Fig. 5.-Probetas de mortero de $1 \times 1 \times 6 \mathrm{~cm}$. Evolución de los coeficientes de corrosión Koch-Steinegger.

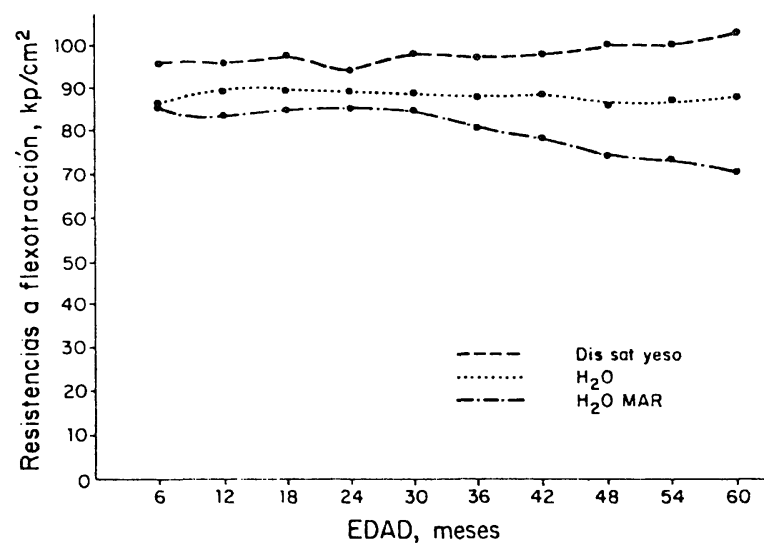

Fig. 6.-Probetas de mortero de $4 \times 4 \times 16 \mathrm{~cm}$. Evolución de las resistencias mecánicas, a flexotracción.

sivas y en agua potable, a flexotracción en la primera (valores medios de 10 probetas por serie, por edad y por disolución agresiva) y a compresión en la segunda (valores medios de las 20 mitades de las 10 probetas anteriores), en $\mathrm{kp} / \mathrm{cm}^{2}$, en función del tiempo de conservación (hasta 5 años).

En ambas figuras se observa que, como en el caso anterior, las resistencias mecánicas de las probetas - tanto a flexotracción, como a compresión- sumergidas en la disolución saturada de yeso son superiores que las correspondientes a las series de probetas conservadas bajo agua potable y éstas, a su vez, mayores que las de las series sumergidas en agua 
de mar artificial, todo lo cual se refleja en la figura 8 , donde puede apreciarse que los coeficientes $R_{t} / R_{t}^{\prime}$, a flexotracción, son mayores que la unidad en los casos de las probetas sumergidas en la disolución saturada de yeso y menores de la unidad, pero mayores de 0,70 en el agua de mar artificial.

Las probetas sometidas a la acción del agua de mar aparecen recubiertas, parcialmente, de una película de $\mathrm{Mg}(\mathrm{OH})_{2}$ análoga a la de la figura 11.

\section{c) Probetas de hormigón de $10 \times 10 \times 40 \mathrm{~cm}$}

En las figuras 9 y 10 se han representado las resistencias mecánicas a flexotracción en la primera (valores medios de 10 probetas por serie, por edad y por disolución agresiva) y a compresión en la segunda (valores medios de las 20 mitades de cada serie de 10 probetas),

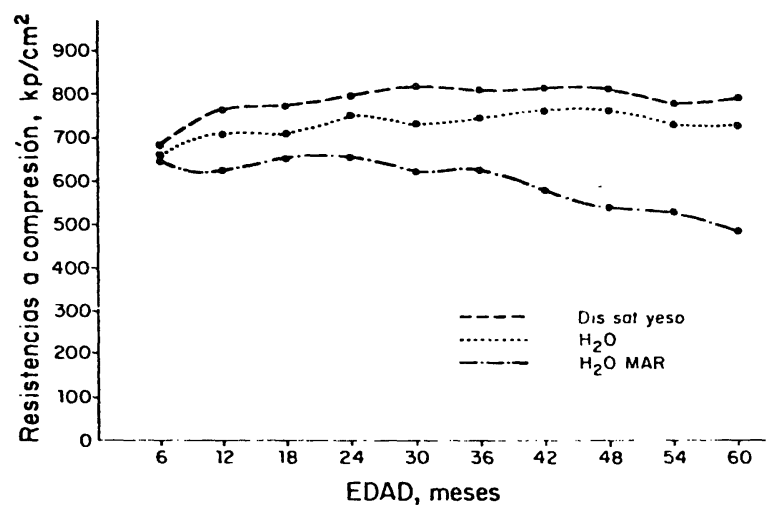

Fig. 7.-Probetas de mortero de $4 \times 4 \times 16 \mathrm{~cm}$. Evolución de las resistencias mecánicas, a compresión.

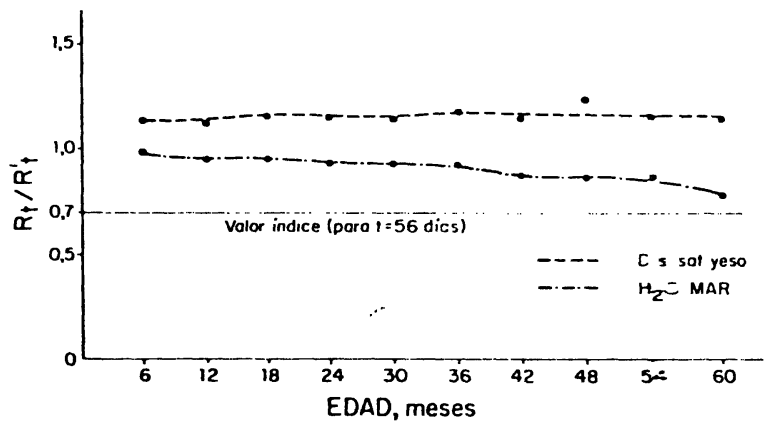

Fig. 8.-Probetas de mortero de $4 \times 4 \times 16 \mathrm{~cm}$. Evolución de los coeficientes $R_{t} / R_{t}^{\prime}$. en $\mathrm{kp} / \mathrm{cm}^{2}$, de las probetas de hormigón sumergidas en las disoluciones agresivas y en agua potable, en función del tiempo de conservación (hasta 5 años).

En estas figuras se puede apreciar que las resistencias mecánicas más altas corresponden, por regla general, a las probetas conservadas en agua potable, seguidas de las correspondientes a las sumergidas en la disolución saturada de yeso y en agua de mar artificial ASTM.

El aspecto de las probetas sometidas a la acción del agua potable y de las disoluciones agresivas era normal a todas las edades, como se puede apreciar en la figura 11, en donde, a título de ejemplo, se encuentran tres fotografías de una probeta de las series sumergidas durante 5 años en agua potable, en la disolución saturada de yeso y en agua de mar artificial ASTM.

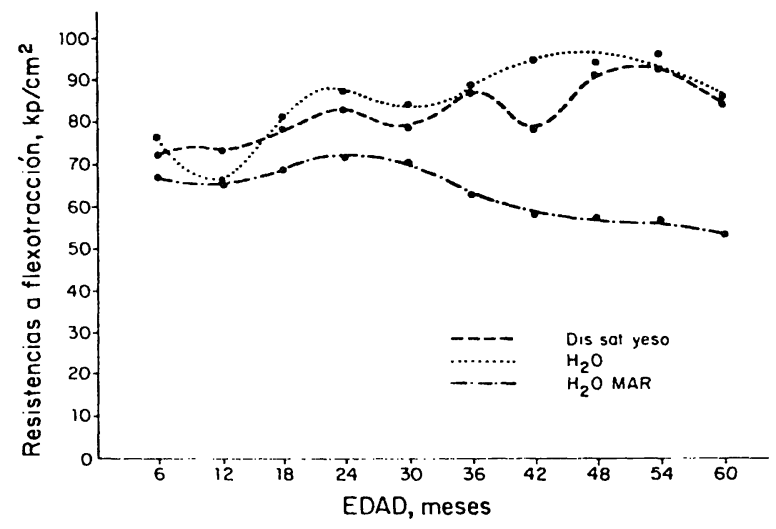

Fig. 9.-Probetas de hormigón, de $10 \times 10 \times 40 \mathrm{~cm}$. Evolución de las resistencias mecánicas a flexotracción.

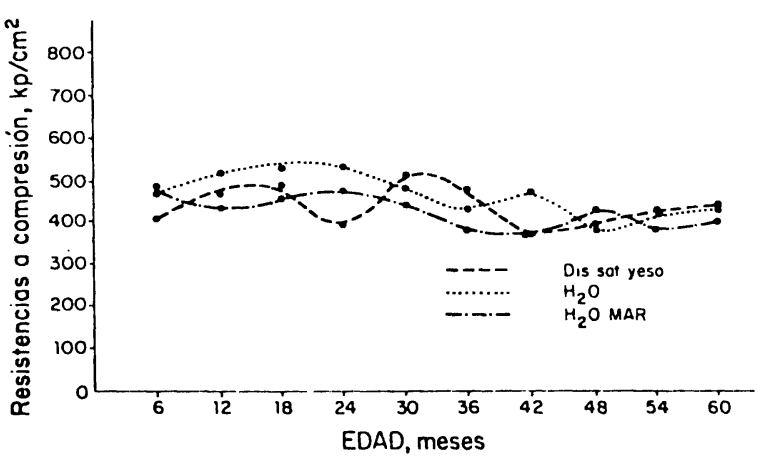

Fig. 10.-Probetas de hormigón de $10 \times 10 \times 40 \mathrm{~cm}$. Evolución de las resistencias mecánicas, a compresión.

MATERIALES DE CONSTRUCCION, Vol. 40, n. 217 , enero/febrero/marzo 1990 




Fig. 11.-Vista de las probetas de hormigón.

\subsubsection{Sistemas: cemento 2/escoria o arena molida-agua potable filtrada}

En la figura 12 se ha representado la evolución de las resistencias mecánicas a flexotracción, en $\mathrm{kp} / \mathrm{cm}^{2}$, de las series de probetas de mortero (1:3) de $1 \times 1 \times 6 \mathrm{~cm}$ (valores medios de 12 probetas por serie y por edad) hechas con el cemento 2 y con las mezclas cemento 2 /escoria y cemento 2 /arena moli$\mathrm{da}=85 / 15-65 / 35-40 / 60$ y $30 / 70$, en peso, sumergidas en agua potable filtrada (hasta 3 años las series fabricadas con las mezclas cemento 2/escoria y hasta 1 año con las mezclas cemento 2/arena molida) después del período de curado $(1+21$ días). En dicha figura se aprecia que la adición de escoria favorece el comportamiento mecánico-resistente (a flexotracción) del cemento 2 y, de un modo especial, el correspondiente a las series de probetas hechas con la mezcla que tiene el $70 \%$ de escoria (en peso). Por el contrario, la adición de arena molida disminuye dicho comportamiento; esta disminución de las resistencias mecánicas es directamente proporcional a la cantidad de arena molida en la mezcla utilizada para fabricar las probetas de mortero. Así, p.e., las resistencias a flexotracción han pasado de 55 a $65 \mathrm{kp} / \mathrm{cm}^{2}$ para las probetas hechas con cemento 2 y a $15-20 \mathrm{kp} / \mathrm{cm}^{2}$ para las probetas hechas con la mezcla que tiene el $70 \%$ de arena molida.

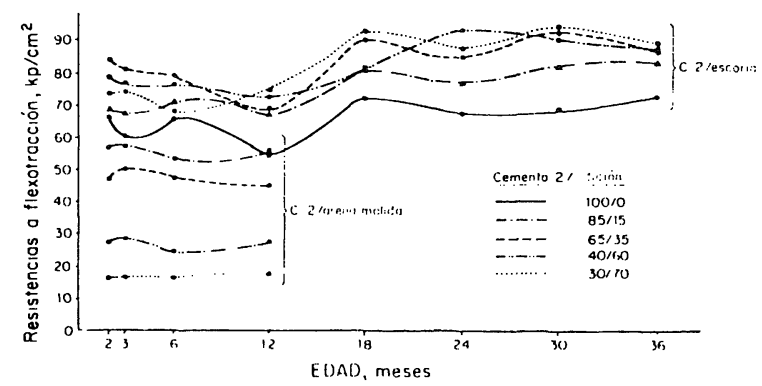

Fig. 12.-Sistemas: C-2/adición-agua potable filtrada. Evolución de las resistencias mecánicas, a flexotracción.

\subsubsection{Sistemas: cemento 2/escoria o arena molida - disolución saturada de yeso}

En la figura 13 se ha representado la evolución de las resistencias mecánicas a flexotracción, en $\mathrm{kp} / \mathrm{cm}^{2}$, de las series de probetas de mortero $(1: 3)$ de $1 \times 1 \times 6 \mathrm{~cm}$ (valores medios de 12 probetas, por serie y por edad) fabricadas con el cemento 2 y con las mezclas cemento 2 /escoria y arena molida, mencionadas anteriormente, y sumergidas en una disolución saturada de yeso (hasta 3 años las series hechas con cemento 2 y con las mezclas cemento 2/escoria y hasta 1 año con las mezclas cemento 2/arena molida) después del período de curado $(1+21$ días $)$. 


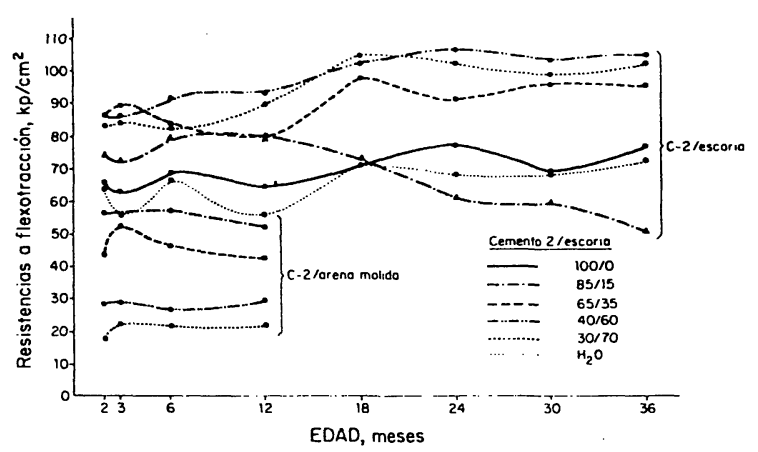

Fig. 13.-Sistemas: C-2/adición-dis. saturada de yeso. Evolución de las resistencias mecánicas, a flexotracción.

La adición de escoria -en cantidades del 35, 60 y $70 \%$, en peso- favorece el comportamiento mecánico-resistente, a flexotracción, del cemento 2 sometido a la acción de una disolución saturada de yeso. Las series de probetas fabricadas con la mezcla que tiene la menor cantidad de escoria (15\%, en peso), presenta valores menores, con tendencia a disminuir a partir de 18 meses, con relación a las series elaboradas con cemento 2 , sumergidas tanto en agua de mar artificial ASTM como en agua potable filtrada.

Del mismo modo que en los casos anteriores, los valores de dichas resistencias, a flexotracción, de las diversas series de probetas de mortero (1:3) hechas con las mezclas cemento 2/arena molida, sumergidas en la disolución saturada de yeso, son menores que las de las series de probetas elaboradas con cemento 2 sumergidas en la disolución saturada de yeso o en agua potable filtrada. Estos valores están intimamente ligados al contenido de arena molida.

\subsubsection{Sistemas: cemento 2/escoria o arena molida - agua de mar artificial ASTM}

En la figura 14 se ha representado la evolucion de las resistencias mecánicas a flexotracción, en $\mathrm{kp} / \mathrm{cm}^{2}$, de las series de probetas de mortero $(1: 3)$ de $1 \times 1 \times 6 \mathrm{~cm}$ (valores medios de 12 probetas por serie y por edad)

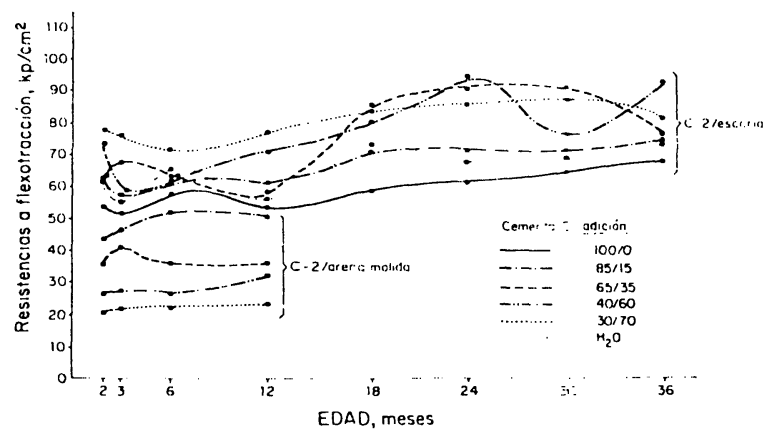

Fig. 14.-Sistemas: C-2/adición-agua mar artificial ASTM. Evolución de las resistencias mecánicas, a flexotracción. hechas con el cemento 2 y con las mismas mezclas de escoria y de arena molida que las del apartado anterior, sumergidas en agua de mar artificial ASTM (hasta 3 años las series fabricadas con el cemento 2 y con las mezclas cemento 2/escoria y hasta 1 año con las mezclas cemento 2/arena molida) después del período de curado $(1+21$ días).

La adición de escoria al cemento 2 favorece, como en el caso anterior, el comportamiento mecánico-resistente, a flexotracción, cuando se somete a la acción del agua de mar artificial ASTM; los valores mayores corresponden, por regla general, a las distintas edades estudiadas, a las series de probetas de mortero $(1: 3)$ elaboradas con la mezcla que tiene la mayor cantidad de escoria (70 \%, en peso), seguidas de las hechas con la mezcla cemento $2 /$ escoria $=40 / 60$ (en peso).

Por el contrario, las probetas fabricadas con las mezclas del cemento 2 con arena molida sumergidas en agua de mar artificial ASTM presentan valores menores - tanto menores, cuanto mayor es la cantidad de arena molidaque los correspondientes a las series hechas con cemento 2 .

Las resistencias mecánicas, a flexotracción, de las series de probetas hechas con la mezcla cemento 2 /escoria $=85 / 15$, en peso, son inferiores o del mismo orden que las de las probetas elaboradas con cemento 2 conservadas en agua potable, mientras que las fabricadas con las mezclas $65 / 35$ y $40 / 60$, en peso, son ligeramente inferiores a 6 meses y superiores en las edades restantes; con la mezcla 30/70, en peso, son superiores a todas las edades y, con el cemento 2 sin adición de escoria, son inferiores.

\subsection{Estudio de la concentración iónica}

En este apartado se expone la evolución del contenido de iones $\mathrm{Ca}$ (II) en el agua potable filtrada y en la disolución saturada de yeso así como de los iones $\mathrm{Ca}$ (II) y $\mathrm{Mg}$ (II) en el agua de mar artificial ASTM, en donde han estado sumergidas las diversas series de probetas de mortero de $1 \times 1 \times 6 \mathrm{~cm}$ durante $56-90$ - 180 y 360 días y en la nueva fase sólida formada en dichos medios.

\subsubsection{Evolución del contenido de $\mathrm{Ca}$ (II)}

\section{a.1) Sistemas: Cemento 2/escoria-disolución agresiva}

La evolución del contenido de iones $\mathrm{Ca}$ (II) - valor medio del correspondiente a las 4 primeras edades, estudiadas por el momento, por 




Fig. 15.-Sistemas: C-2/escoria-dis. agresiva. Evolución del contenido de $\mathrm{Ca}$ (II) $<>\mathrm{Ca}(\mathrm{OH})_{2}$ disuelto.

serie de probetas - en función de la mezcla cemento 2/escoria utilizada para fabricar las diversas series de probetas de mortero, que se han sumergido en el agua potable filtrada, en la disolución saturada de yeso y en el agua de mar artificial ASTM, se ha representado en la figura 15, en cuya figura se aprecia que las cantidades de $\mathrm{Ca}(\mathrm{II}) / 800 \mathrm{ml}<>\mathrm{Ca}(\mathrm{OH})_{2}$ disuelto (fundamentalmente) que se encuentra en la disolución y en la nueva fase sólida, en cada caso, disminuye conforme lo hace el contenido de clínker en la mezcla cemento 2/escoria.

Las cantidades disueltas son menores que las teóricas (calculadas a partir del $\mathrm{Ca}$ (II) encontrado en la disolución y en la nueva fase sólida formada en el medio en donde han estado las probetas hechas con cemento 2) debido a la presencia de la escoria que al reaccionar con parte del $\mathrm{Ca}(\mathrm{OH})_{2}$ naciente, generado en las reacciones de hidratación, forma los compuestos correspondientes. Esta disminución es función lineal en el caso de las probetas sumergidas en agua de mar artificial y ligeramente exponencial en los otros dos casos.

El Ca (II) que aparece en el agua potable filtrada y en la nueva fase sólida formada procede, fundamentalmente, de la disolución de parte del $\mathrm{Ca}(\mathrm{OH})_{2}$ formado durante las reaciones de hidratación de la fracción clínker (dada la solubilidad de los compuestos de calcio del cemento hidratado) y que no haya reaccionado con la escoria, según la reacción $(A)$ :

$$
\text { (A) } \mathrm{Ca}(\mathrm{OH})_{2} \text {.sólido } \rightleftharpoons \mathrm{Ca} \text { (II) }+2 \mathrm{OH} \text { (I) }
$$

dando lugar, además, a un incremento de los grupos $\mathrm{OH}$ (I) $\mathrm{y}$, por tanto, del valor del $\mathrm{pH}$, llegando a alcanzar valores superiores a 11.

Cuando el medio de conservación-ataque de las series de probetas de mortero ha sido la disolución saturada de yeso, el equilibrio (A) se ve afectado por la presencia del ion común $\mathrm{Ca}$ (II) de la disolución, lo que hace que las cantidades disueltas de $\mathrm{Ca}(\mathrm{OH})_{2}$ sean menores que las correspondientes a las series de probetas análogas sumergidas en agua potable filtrada. Por el contrario, dichas cantidades son mayores cuando las series de probetas de mortero -análogas a éstas- han estado sumergidas en el agua de mar artificial; en efecto, el equilibrio (A) se ve influenciado por la presencia de los iones presentes en el agua de mar artificial ASTM, de un modo especial por los no comunes distintos del $\mathrm{Ca}$ (II) y, además, por la existencia de dichos iones u otros compuestos que dan lugar a reacciones de precipitación con los iones $\mathrm{Ca}$ (II) o con los iones $\mathrm{OH}$ (I) del mencionado equilibrio (A), como sucede con los iones $\mathrm{Mg}$ (II) y $\mathrm{SO}_{4}$ (II) y con el $\mathrm{CO}_{2}$, según:

$$
\begin{aligned}
& \mathrm{Ca}(\mathrm{II})+2 \mathrm{OH}(\mathrm{I})+\mathrm{CO}_{2} \rightleftharpoons \\
& \rightleftharpoons \mathrm{CaCO}_{3} \text {.solido }+\mathrm{H}_{2} \mathrm{O} \\
& \mathrm{Ca}(\mathrm{II})+\mathrm{SO}_{4}(\mathrm{II})+\mathrm{H}_{2} \mathrm{O} \rightleftharpoons \\
& \rightleftharpoons \mathrm{CaSO}_{4} .2 \mathrm{H}_{2} \text { O.sólido }
\end{aligned}
$$

$\mathrm{Ca}\left(\right.$ II) $+\mathrm{SO}_{4}\left(\right.$ II) $+\mathrm{H}_{2} \mathrm{O} \rightleftharpoons$

$\mathrm{Mg}(\mathrm{II})+2 \mathrm{OH}(\mathrm{I}) \rightleftharpoons \mathrm{Mg}(\mathrm{OH})_{2}$.solido

que producen, en un grado determinado, la disminución de iones $\mathrm{Ca}$ (II) y $\mathrm{OH}$ (I) en el medio, favoreciendo, así mismo, la disolución de los compuestos de calcio y, de un modo especial, del $\mathrm{Ca}(\mathrm{OH})_{2}$, así como el avance de las reacciones de hidratación, fenómenos que, a su vez, son función del tiempo de conservación-ataque de las probetas para cada mezcla, como se ha probado por DRX (de este estudio se dará cuenta en otras publicaciones).

\section{a.2) Sistemas: Cemento 2/arena-disolución agresiva}

En la figura 16 se ha representado, como en la figura 15, la evolución del valor medio correspondiente a las 4 edades estudiadas, por el momento, del contenido de $\mathrm{Ca}$ (II) en la disolución $(800 \mathrm{ml})$ y en la nueva fase sólida formada, en función de las mezclas cemento 


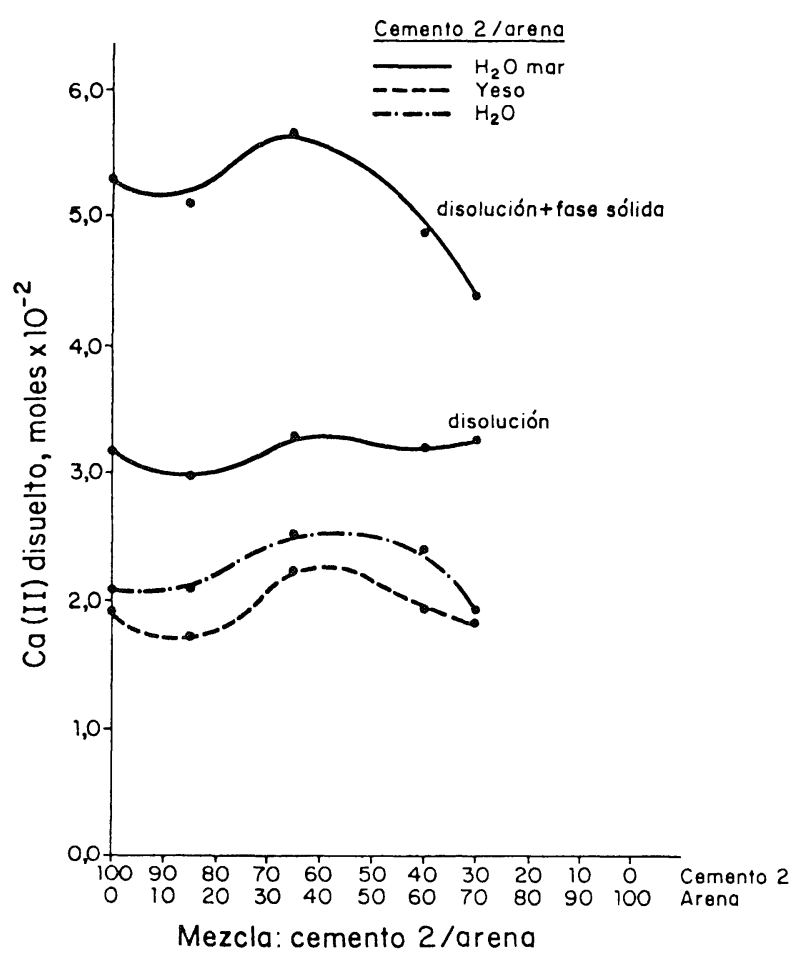

Fig. 16.-Sistemas: C-2/arena-dis. agresiva. Evolución del contenido de $\mathrm{Ca}$ (II) $<>\mathrm{Ca}(\mathrm{OH})_{2}$ disuelto.

2/arena utilizada para fabricar las diversas series de probetas de mortero, las cuales se han sumergido en los tres medios mencionados.

Las cantidades de $\mathrm{Ca}$ (II) $<>\mathrm{Ca}(\mathrm{OH})_{2}$. disuelto (fundamentalmente) en los $800 \mathrm{ml}$ dependen, como en el caso anterior, del medio de conservación; las menores corresponden a la disolución saturada de yeso, y las mayores al agua de mar artificial ASTM. Dichas cantidades, independientemente del contenido de clínker en la mezcla cemento/arena, se encuentran comprendidas dentro de los siguientes entornos: $2,21 \times 10^{-2}$ moles - $1,73 \times 10^{-2}$ moles para la disolución saturada de yeso; $2,58 \times$ $\times 10^{-2}$ moles - $1,88 \times 10^{-2}$ moles para el agua potable filtrada, y $5,68 \times 10^{-2}$ moles $-4,34 \times$ $\times 10^{-2}$ moles para el agua de mar artificial ASTM, como consecuencia de las características inertes de la arena por una parte, y de la influencia del catión $\mathrm{Ca}$ (II) en la disolución saturada de yeso por otra, y de los iones $\mathrm{Ma}$ (II), $\mathrm{SO}_{4}$ (II) y del $\mathrm{CO}_{2}$ en el agua de mar artificial ASTM.

\subsubsection{Evolución del contenido de $\mathrm{Mg}(\mathrm{II})$}

\section{b.1) Sistemas: cemento 2/escoria o arena-} agua de mar artificial ASTM

El contenido de $\mathrm{Mg}$ (II) en el agua de mar artificial ASTM $\left(4,43 \times 10^{-2}\right.$ moles $\left./ 800 \mathrm{ml}\right)$-en donde han estado las probetas de mortero durante las 4 edades estudiadas, hechas con ce- mento y con la mezcla cemento 2/escoria $=$ $=85 / 15$ (en peso) - ha desaparecido, prácticamente, habiendo precipitado como $\mathrm{Mg}(\mathrm{OH})_{2}$ tanto en las probetas como en la disolución, dando lugar a la nueva fase sólida, junto con la calcita y el aragonito, como se ha probado por DRX (4); sin embargo, en los diversos sistemas cemento 2/arena (análogos a los de cemento 2/escoria) el $\mathrm{Mg}$ (II) ha desaparecido prácticamente del agua de mar, habiendo precipitado en la nueva fase sólida - junto con la calcita, el aragonito, la halita y la gehlenitacomo $\mathrm{Mg}(\mathrm{OH})_{2}$ (en cantidades análogas a las del medio en donde han estado las probetas hechas con cemento 2) y en las probetas de mortero, como se ha probado por DRX (del estudio correspondiente se dará cuenta en otras publicaciones).

El Mg (II) que existe en el agua de mar artificial ASTM reacciona a $\mathrm{pH}>10$ con los iones $\mathrm{OH}(\mathrm{I})$ del equilibrio $(\mathrm{A})$, según la reacción (D), precipitando como $\mathrm{Mg}(\mathrm{OH})_{2}$ por cumplirse [Mg (II)] $[\mathrm{OH}(\mathrm{I})]^{2}>$ Ps $\left(1,8 \times 10^{-11}\right)$; en los medios $(800 \mathrm{ml})$ en donde han estado las series de probetas hechas con cemento 2 y con las mezclas cemento 2 /arena $=85 / 15-65 / 35$ y $40 / 60$ (en peso) y cemento $2 /$ escoria $=85 / 15$, el $\mathrm{pH}$ es mayor de 10,5 (por regla general, es superior a 11) debido a la cantidad de $\mathrm{Ca}(\mathrm{OH})_{2}$ disuelto y a la influencia de las características de la adición (fig. 17). Por el contrario, en el agua de mar en donde han estado sumergidas las probetas de mortero fabricadas con las mezclas cemento 2 /escoria $=65 / 35-40 / 60$ y $30 / 70$ (en peso), no ha precipitado en la diso-

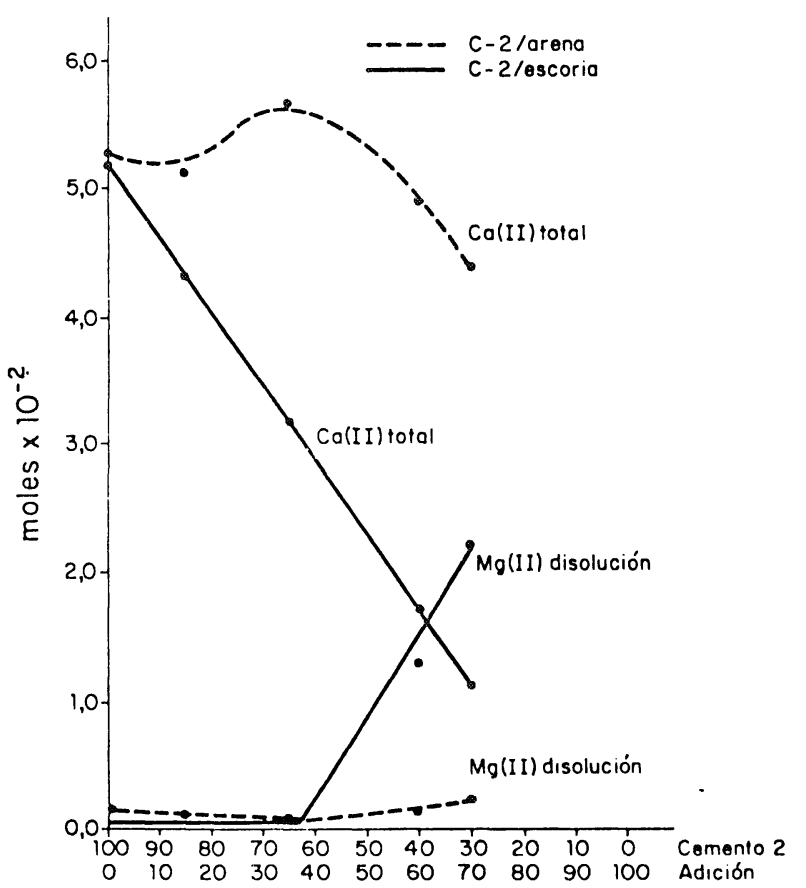

Fig. 17.-Sistemas: C-2/adición-agua mar artificial ASTM. Evolución del contenido de $\mathrm{Ca}$ (II) $<>\mathrm{Ca}(\mathrm{OH})_{2}$ disuelto y $\mathrm{Mg}$ (II) en la disolución. 
lución por no darse las condiciones adecuadas y no alcanzarse el Ps, así como con la mezcla que tiene el mayor contenido de arena (70\%); sin embargo, mientras que en el agua de mar artificial ASTM en donde han estado las probetas hechas con la mezcla cemento $2 /$ arena $=30 / 70$ (en peso), las cantidades de $\mathrm{Mg}$ (II) que existen son menores de 0,60 $\times 10^{-2}$ moles $/ 800 \mathrm{ml}$ (habiendo precipitado el resto en las probetas de mortero, en su mayor parte, y en la nueva fase sólida), en dicha agua de mar artificial ASTM, en donde se sumergieron las series de probetas fabricadas con las mezclas cemento 2/escoria mencionadas, se encuentran en cantidades mayores de 2,0 $\times 10^{-2}$ moles $/ 800 \mathrm{ml}$, y el resto, prácticamente, en las probetas de mortero como $\mathrm{Mg}(\mathrm{OH})_{2}$.

\subsection{Estudio de la nueva fase sólida}

En los tres medios, en donde han estado sumergidas las distintas series de probetas de mortero de $1 \times 1 \times 6 \mathrm{~cm}$, se ha formado una nueva fase sólida en la que, por DRX, se han identificado los picos de los siguientes compuestos cristalinos:

\section{a) Sistemas: cemento 2/adición-agua potable filtrada}

En la nueva fase sólida, formada en el agua potable filtrada, en donde se han conservado las probetas de mortero hechas con cemento 2 y con cemento 2/arena $=85 / 15$ y 65/35 y $30 / 70$, en algunos casos (en peso), se han detectado los picos de los compuestos cristalinos calcita y aragonito (los picos de este último son de intensidad menor que los de la calcita), mientras que en la nueva fase formada en el agua potable filtrada, en donde se sumergieron las probetas de mortero fabricadas con las diversas mezclas cemento 2/escoria y con cemento 2/arena $=40 / 60$ y $30 / 70$, en algunos casos (en peso), únicamente se han identificado los picos de la calcita.

En la formación de estos compuestos ha influido la cantidad de $\mathrm{Ca}$ (II) liberado procedente, de un modo especial, del $\mathrm{Ca}(\mathrm{OH})_{2}$ disuelto (es del mismo orden en los medios donde han estado las probetas hechas con cemento 2 y con las mezclas cemento 2/arena) y la concentración de iones $\mathrm{OH}$ (I) que proporcionan un $\mathrm{pH}$ superior a 11 en estos casos.

\section{b) Sistemas: cemento 2/adición-disolución saturada de yeso}

Como en el caso anterior, en la nueva fase sólida formada en la disolución saturada de yeso, en donde se sumergieron las probetas de mortero, se han detectado los picos de la calcita en todos los casos y, además, los del aragonito (con intensidad menor), en donde estuvieron las series de probetas fabricadas con cemento 2 , con las mezclas cemento 2/ /escoria $=85 / 15$ (en peso) y con todas las mezclas cemento 2/arena.

Asimismo, en la formación de unos y otros compuestos cristalinos, cuyos picos se han identificado en la nueva fase sólida, ha influido la cantidad de $\mathrm{Ca}$ (II) liberado (es del mismo orden en cada uno de los $800 \mathrm{ml}$ de la disolución saturada de yeso, en donde se ha formado aragonito) y la concentración de iones $\mathrm{OH}(\mathrm{I})$; el pH, en estos casos, es superior a 11.

\section{c) Sistemas: cemento 2/adición-agua de mar artificial ASTM}

En la nueva fase sólida, formada en estos sistemas, se han detectado los picos de los siguientes compuestos cristalinos:

c.1) Calcita y aragonito en todos los casos estudiados. La intensidad de los picos de la calcita es mayor que la de los del aragonito en las nuevas fases sólidas formadas en donde han estado sumergidas las series de probetas hechas con el cemento 2 , con la mezcla cemento 2 /escoria $=85 / 15$ (en peso) y con las diversas mezclas cemento 2/arena; en estos casos el pH es superior a 10,5. Las cantidades de $\mathrm{Ca}$ (II) $<>\mathrm{Ca}(\mathrm{OH})_{2}$ disuelto (fundamentalmente) son mayores de $4 \times 10^{-2}$ moles $/ 800 \mathrm{ml}$ y las de $\mathrm{Mg}$ (II) en la disolución, prácticamente nulas.

Por el contrario, dicha intensidad de los picos de la calcita es menor que la de los picos del aragonito en las fases sólidas formadas en el agua de mar artificial ASTM, en donde han estado las probetas de mortero hechas con las mezclas cemento 2/escoria $=40 / 60$ y $30 / 70$ (en peso). En estos casos, el pH se encuentra comprendido entre 7,8 y 8,0 ; la concentración de $\mathrm{Ca}$ (II) es superior a 1,3 $\times 10^{-2}$ moles $/ 800 \mathrm{ml}$ e inferior a $3,5 \times 10^{-2}$ moles $/ 800$ $\mathrm{ml}$, y el contenido de $\mathrm{Mg}$ (II) es mayor de $1,1 \times$ $\times 10^{-2}$ moles $/ 800 \mathrm{ml}$ y menor de $3,1 \times 10^{-2}$ moles/800 ml.

c.2) Brucita en las fases sólidas formadas en el agua de mar artificial ASTM, en donde han estado las series de probetas hechas con cemento 2, con las mezclas cemento 2 /escoria $=$ $=85 / 15$ (en peso) y cemento $2 /$ arena $=85 / 15$, $65 / 35$ y $40 / 60$ en algunos casos (en peso), en cuya agua de mar artificial ASTM el pH es superior a 10,5 y la concentración de $\mathrm{Ca}$ (II) es superior a $3,5 \times 10^{-2}$ moles $/ 800 \mathrm{ml}$ y nula la de $\mathrm{Mg}$ (II). 
c.3) Halita y gehlenita en donde han estado las diversas series de probetas de mortero hechas con las mezclas cemento 2/arena.

c.4) Yeso, en algunos casos.

\subsection{Estudio de la fracción enriquecida}

Las fracciones enriquecidas extraidas de varias probetas de cada serie (fabricadas con cemento 2 y con las distintas mezclas cemento 2 /escoria o cemento 2/arena), sumergidas en las disoluciones agresivas estudiadas en este caso durante 56 - 90 - 180 y 360 días, por el momento, se ha hecho el estudio por DRX, habiendo identificado los picos de los compuestos cristalinos que se citan a continuación.

\subsubsection{Sistemas: cemento 2/adición-agua potable filtrada}

a) Ettringita, en todos los DRX. Mientras que la intensidad de los picos de este compuesto disminuye por regla general, en los diagramas de las fracciones extraidas de las series de probetas hechas con las diversas mezclas cemento 2/escoria (5) (con relación a los correspondientes de las probetas elaboradas con cemento 2, conforme lo hace el contenido de cemento), sin embargo, en los DRX de las fracciones extraidas de las probetas fabricadas con las diversas mezclas cemento 2/arena, dicha intensidad es igual o ligeramente mayor.

\section{b) Yeso en algunos DRX}

c) Portlandita, en todos los DRX (excepto en los de la fracción que corresponde a la mezcla cemento 2 /adición $=30 / 70$, para la edad de 360 días). La intensidad de los picos, en los DRX correspondientes, disminuye en ambos casos conforme lo hace la cantidad de clínker en la mezcla utilizada para fabricar las probetas de mortero. Esta disminución es mayor en los diagramas de las fracciones extraidas de las probetas hechas con las diversas mezclas cemento 2/escoria, que en los análogos de las mezclas cemento 2/arena, como consecuencia de las reacciones que tienen lugar entre la escoria y el $\mathrm{Ca}(\mathrm{OH})_{2}$ naciente generado en las reacciones de hidratación. Dicho fenómeno está de acuerdo con la menor cantidad de $\mathrm{Ca}$ (II) $<>\mathrm{Ca}(\mathrm{OH})_{2}$ disuelto (fundamentalmente), como se ha mencionado en 3.2.1. (Figs. 15 y 16).

\section{d) Calcita, en todos los DRX.}

e) Cuarzo- $\alpha$, en todos los DRX. Los picos de este compuesto en los diagramas obtenidos corresponden a la arena utilizada para preparar las probetas de mortero y, además, a las distintas cantidades de arena molida empleada en las mezclas cemento 2/arena, cuyas intensidades reflejan cuantitativamente esta adición.

\subsubsection{Sistemas: cemento 2/adición-disolución saturada de yeso}

a) Ettringita, en todos los DRX. En los DRX de las fracciones enriquecidas extraidas de las series de probetas hechas con cemento 2 y con cemento 2/escoria los picos de mayor intensidad corresponden a la mezcla que tiene $15 \%$ de escoria (en peso) y los de menor, a la que tiene $70 \%$ de escoria (en peso).

Los picos de los DRX de todas las fracciones enriquecidas extraidas de las series de probetas elaboradas con las diversas mezclas cemento 2/arena, tiene mayor intensidad que las correspondientes a los DRX de las fracciones extraidas de las probetas fabricadas con cemento 2. La mayor intensidad corresponde a los DRX de las fracciones enriquecidas de las series de probetas hechas con las mayores cantidades de arena, que, asimismo, es mayor que la de los DRX de las series de probetas análogas de las mezclas cemento 2/escoria (Figura 18).

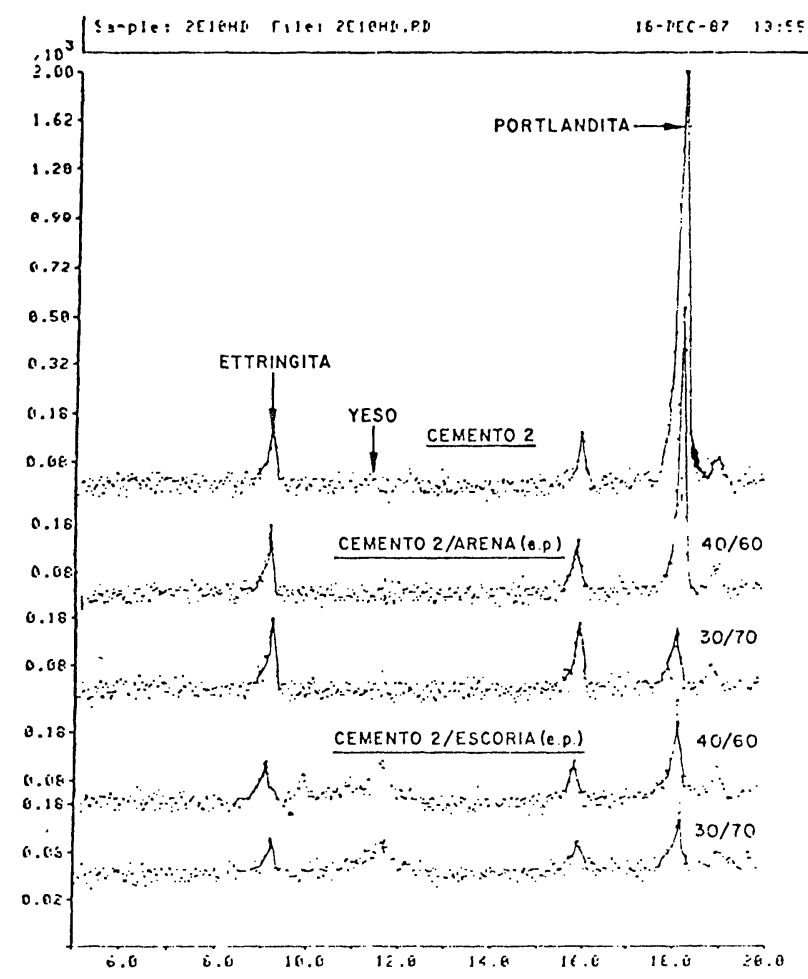

Fig. 18.-Sistemas: C-2/adición-dis. saturada de yeso Fracciones enriquecidas (pasta hidratada-atacada). DRX. 
La intensidad de estos picos es mayor que la de los diagramas de las fracciones extraidas de las probetas hechas con cemento 2/adición (escoria o arena) sumergidas en agua potable filtrada, por la influencia de las características de la disolución saturada de yeso.

b) Yeso. Los picos de este compuesto, únicamente se han detectado en las fracciones enriquecidas extraidas de las probetas hechas con cemento 2 /escoria $=85 / 15$ (una edad), $65 / 35$ (cuatro edades), 40/60 (dos edades) y $30 / 70$ (dos edades).

c) Portlandita, en todos los DRX. La intensidad de los picos, en los DRX correspondientes, disminuye, como en el caso anterior, conforme lo hace la cantidad de clínker en la mezcla utilizada (cemento 2 con escoria o con arena molida) para fabricar las probetas de mortero. Esta disminución es mayor cuando se trata de los diagramas de las fracciones enriquecidas correspondientes a las probetas hechas con las diversas mezclas cemento 2 /escoria (figura 18), que los análogos de las mezclas cemento 2/arena, como consecuencia de las reacciones que tienen lugar entre la escoria y el $\mathrm{Ca}(\mathrm{OH})_{2}$ naciente. Estos fenómenos están de acuerdo con la menor cantidad de $\mathrm{Ca}$ (II) $<>\mathrm{Ca}(\mathrm{OH})_{2}$ disuelto (fundamentalmente), como se ha mencionado en 3.2.1.

\section{d) Calcita, en todos los DRX}

e) Vaterita, en determinados diagramas que corresponden a las fracciones extraidas de las probetas hechas con cemento 2 (una edad) y con cemento 2 /escoria $=85 / 15$ (dos edades), 65/35 (una edad), 40/60 (una edad) y 30/70 (tres edades).

f) Cuarzo- $\alpha$, en todos los DRX, como sucede en 3.4.1.

\subsubsection{Sistemas: cemento 2/adición-agua de mar artificial ASTM}

a) Ettringita, prácticamente en todos los DRX. La intensidad de los picos de este compuesto es del mismo orden en los diagramas de las fracciones extraidas de las series de probetas hechas con la mezcla cemento 2/escoria = $=85 / 15$ (en peso) que la correspondiente a la de los DRX de las series fabricadas con cemento 2, y menor en los diagramas de las fracciones extraidas de las probetas elaboradas con cemento $2 /$ escoria $=65 / 35,40 / 60$ y $30 / 70$ (en peso); sin embargo, dicha intensidad es del mismo orden o ligeramente mayor en los diagramas de las fracciones extraidas de las diversas series de probetas hechas con las mezclas cemento 2/arena molida estudiadas. b) Yeso, en los DRX de las fracciones extraidas de las series de probetas hechas con las mezclas cemento 2/escoria $=85 / 15-65 / 35$ y $40 / 60$ (en peso) y en todos los diagramas correspondientes a las probetas elaboradas con cemento 2 y con las diversas mezclas cemento 2/arena molida, debido a la formación de $\mathrm{CaSO}_{4} .2 \mathrm{H}_{2} \mathrm{O}$ por reacción de los iones $\mathrm{SO}_{4}$ (II) del agua de mar artificial ASTM con el Ca (II) del $\mathrm{Ca}(\mathrm{OH})_{2}$ presente en las probetas de mortero; parte del cual, al reaccionar con los aluminatos de calcio hidratados, da lugar a la ettringita. La intensidad de los picos de este compuesto es mayor en los diagramas de las fracciones extraidas de las probetas fabricadas con las mezclas cemento 2 /escoria $=85 / 15$ y $65 / 35$ (en peso) y con todas las mezclas cemento 2/arena molida, que la de los DRX de las fracciones de las probetas hechas con cemento 2 , y de un modo especial la de las series de probetas elaboradas con las mezclas que tienen los mayores contenidos de arena molida (60 y $70 \%$, en peso).

c) Portlandita, en los DRX de las fracciones extraidas de las probetas hechas con cemento 2 , con las mezclas cemento 2/arena (excepto en tres casos, de 20) y cemento 2 /escoria $=$ $85 / 15$ y $65 / 35$ (en peso), no habiéndose detectado en los casos restantes. La intensidad de los picos disminuye conforme to hace la cantidad de cemento en la mezcla y, como en los casos anteriores, depende de las características de la escoria, además de la presencia del ion $\mathrm{Mg}$ (II) en el agua de mar por las razones expuestas en 3.2.2.; fenómenos que influyen en las cantidades de $\mathrm{Ca}(\mathrm{OH})_{2}$ disuelto y de $\mathrm{Mg}$ (II) presente en el agua de mar artificial ASTM y en la nueva fase sólida (apartados 3.2.1. y 3.2.2.)

d) Calcita, en todos los DRX

c) Brucita, en todos los DRX. La intensidad de los picos de las fracciones extraidas de las series de probetas hechas con las mezclas cemento 2 /escoria $=65 / 35$ y $40 / 60$ (en peso) y cemento $2 /$ arena $=40 / 60$ y $30 / 70$ (en peso), fundamentalmente, es mayor que la correspondiente a la de las probetas fabricadas con cemento 2; estos procesos se corresponden con las cantidades de $\mathrm{Mg}$ (II) en el agua de mar artificial ASTM y en la nueva fase sólida (fig. 17 y apartado 3.2.2.).

f) Sal de Friedel, en los DRX de las fracciones enriquecidas extraidas de las series de probetas hechas con las mezclas cemento 2/escoria $=65 / 35,40 / 60$ y $30 / 70$ (en peso); como se mencionó en (4), en la formación de este compuesto han influido las características de la escoria y su cantidad.

h) Cuarzo- $\alpha$, en todos los DRX. La intensidad de los picos es análoga a la de los dos sistemas anteriores (3.4.1. y 3.4.2.). 

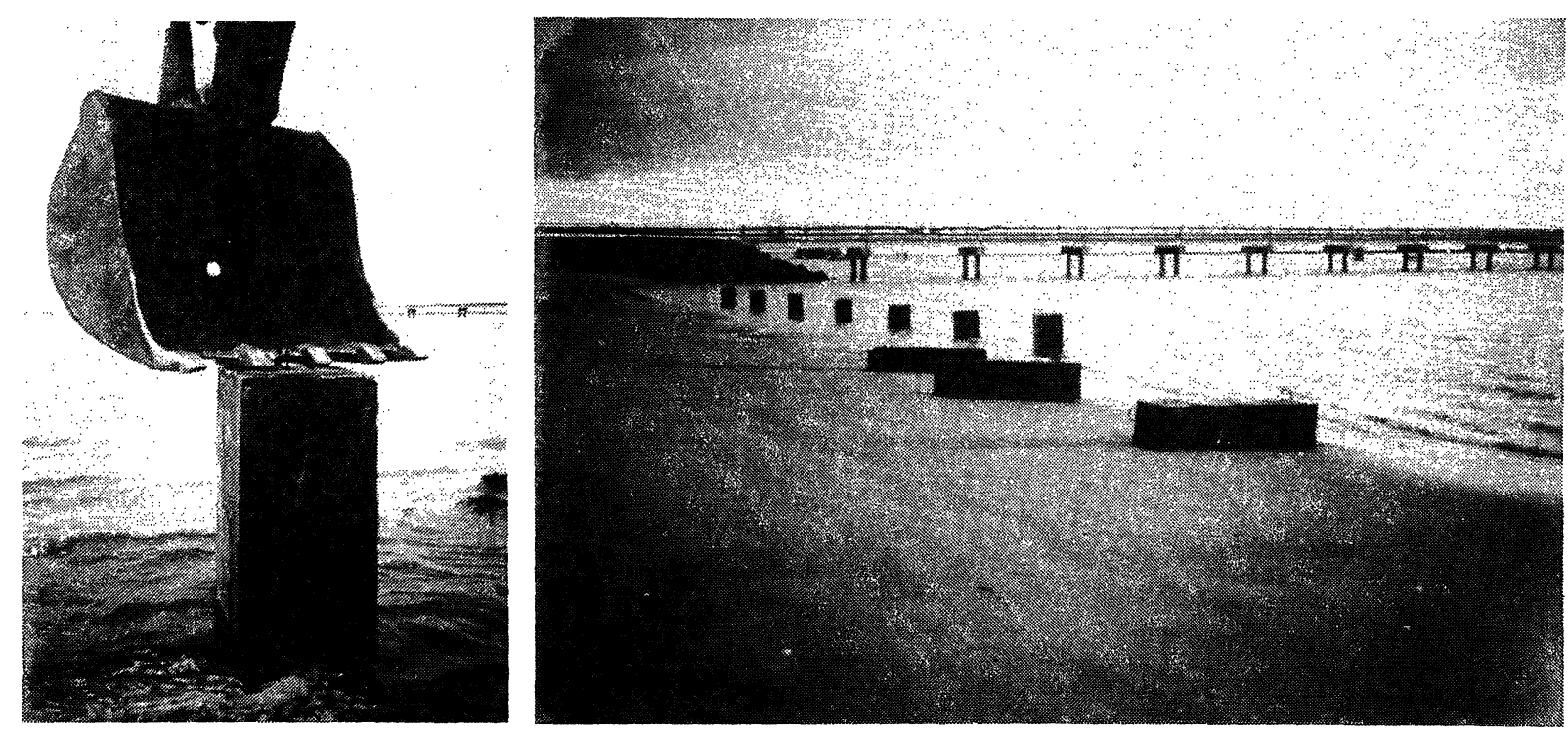

Fig. 19.-Trabajos en agua mar. Emplazamiento: Puerto Autónomo de Huelva.

\section{TRABAJOS EN MEDIOS NATURALES}

A la vista de los resultados obtenidos - de los que, en parte, se da cuenta en este trabajocon diversos cementos de características estructurales distintas y adiciones (una escoria y tres cenizas volantes, en una primera etapa, elegidas por los estudios previos realizados con 19 cenizas volantes), y con el fin de ampliarlos y conocer el comportamiento de los hormigones a escala real cuando se someten a la acción de medios agresivos naturales, se han iniciado recientemente otros trabajos en un lugar seleccionado de la Zona de Servicio del Puerto Autónomo de Huelva (Fig. 19), por sus características especiales, en donde se han situado 120 bloques de hormigón armado (cuyas dimensiones son: $2,00 \times 0,50 \times 0,50$ m) en esta etapa previa, los cuales se han hecho con dos cementos portland -elegidos como consecuencia de los trabajos efectuados-, 1.200 probetas cilíndricas $\varnothing=15 \mathrm{~cm} \times$ $\times h=30 \mathrm{~cm})$ de hormigón y 1.440 probetas prismáticas $(4 \times 4 \times 16 \mathrm{~cm})$ de mortero. De los trabajos efectuados, así como del Programa de Trabajo a desarrollar en 15 años, se dará cuenta en otras publicaciones.

\section{RESUMEN Y CONCLUSIONES}

En este trabajo se hace un estudio comparativo entre las diversas series de probetas de mortero $(1: 3)$ fabricadas con un cemento portland resistente al yeso y con sus mezclas con una escoria siderúrgica seleccionada por una parte, y con una arena silícea molida, por otra, cuando se someten a la acción de una disolución saturada de yeso y a la del agua de mar artificial ASTM, así como a la del agua potable filtrada, habiéndose puesto de manifiesto:

Primero: La influencia beneficiosa que ejerce la adición de la escoria al cemento portland resistente al yeso (casos estudiados en este trabajo) cuando las diversas series de probetas de mortero se someten durante distintos periodos de tiempo (hasta 3 años) a la acción de las disoluciones agresivas y del agua potable filtrada mencionadas.

Con todas las mezclas estudiadas, se ha producido un incremento de las resistencias mecánicas a flexotracción; los mejores resultados -a lo largo de los tres años estudiados, por el momento- corresponden a las series de probetas hechas con las mezclas que tienen los mayores contenidos de escoria, lo que permite establecer el siguiente orden: Cemento 2/escoria $=30 / 70>65 / 35>40 / 60>85 / 15>$ $>100 / 0 ; 40 / 60>30 / 70>65 / 35>85 / 15>$ $>100 / 0$ y $30 / 70>40 / 60>85 / 15>100 / 0$, en el caso de que dichas series de probetas se hayan sometido a la acción del agua potable filtrada, de la disolución saturada de $\mathrm{CaSO}_{4} .2 \mathrm{H}_{2} \mathrm{O}$ o del agua de mar artificial ASTM respectivamente. Por el contrario, las series de probetas de mortero (1:3) fabricadas con las mezclas cemento 2/arena silícea molida experimentan un descenso de las resistencias mecánicas a flexotracción, inversamente proporcional a la cantidad de cemento.

Segundo: Mientras que la cantidad (valores medios) de $\mathrm{Ca}$ (II) $<>\mathrm{Ca}(\mathrm{OH})_{2}$ disuelto, fundamentalmente, experimenta un descenso en todos los casos estudiados correspondientes 
a las series de probetas hechas con las mezclas cemento 2/escoria (que es función del contenido de cemento en la mezcla y del medio de conservación-ataque); dicha cantidad de $\mathrm{Ca}$ (II) permanece prácticamente constante, dentro de un entorno, cuando se trata de las series de probetas fabricadas con las distintas mezclas cemento 2/arena molida.

Tercero: El Mg (II) del agua de mar artificial ASTM - donde han estado las series de probetas de mortero hechas con cemento 2, con todas las mezclas cemento 2/arena molida y con las que tienen el $15 \%$ de escoria- ha desaparecido prácticamente, habiendo precipitado como brucita en las probetas y en la disolución. En el agua de mar artificial ASTM, en donde se han sumergido las series de probetas fabricadas con las mezclas cemento 2/escoria restantes, dicho $\mathrm{Mg}$ (II) ha desaparecido parcialmente habiendo precipitado en la pasta de cemento como brucita.

Cuarto: Cuando se utiliza la escoria como adición del cemento se producen dos efectos: uno de dilución y otro reactivo, en virtud de lo cual se forman nuevos compuestos como consecuencia de las reacciones de hidratación, mientras que cuando se emplea la arena silicea molida sólamente, se produce un efecto de dilución, habiendo favorecido la formación de determinados compuestos en la pasta de cemento hidratado, entre los que cabe citar la ettringita, el yeso y la brucita.

\section{BIBLIOGRAFIA}

(1) GASPAR-TEBAR, D. (1981): Durabilidad del hormigón, Programa de Investigación del IETcc. Informes de la Construcción, 330, 41-50.

(2) GARCIA DE PAREDES, P. (1967): Inalterabilidad de los conglomerantes al ataque de los sulfatos. Comparación de métodos para apreciarla. Cuadernos de Investigación del IETcc (Madrid); pp. 11-14.

(3) Pliego de Prescripciones Técnicas Generales para la Recepción de cemento, 1975. (RC-75): MOP, Servicio de Publicaciones. Madrid, 1975.

(4) GASPAR-TEBAR, D. y SAGRERA-MORENO, J. L. (1982): Resistencia química del hormigón. XVIII. Acción del agua de mar: influencia de la adición de escoria a un cemento portland resistente al yeso. Estudio por DRX. Materiales de Construcción, 188, 37-58.

(5) SAGRERA-MORENO, J. L. y GASPAR-TEBAR, D. (1981): Resistencia química del hormigón. X. Influencia de la adición de escoria a un cemento portland resistente al yeso. Estudio por DRX del sistema cemento 2/escoria-agua potable filtrada. Materiales de Construcción, 182, 11-22.

\section{AGRADECIMIENTO}

Nuestro más sincero agradecimiento a las personas del Equipo de "Durabilidad del hormigón" del ICCET:Amalia Rodríguez Pereira, Lucila López Solana, M. ${ }^{a}$ Soledad Cid Fernandez, Felipe Cantero Palacios y Manuel Cantero Palacios por su valiosa colaboración en la realización de este trabajo. 